\title{
Probiotic Lactobacillus gasseri SBT2055 improves insulin secretion in a diabetic rat model
}

\author{
M. Niibo, ${ }^{1 *}$ B. Shirouchi, ${ }^{1 *}$ M. Umegatani, ${ }^{1}$ Y. Morita, ${ }^{1}$ A. Ogawa, ${ }^{2}$ F. Sakai, ${ }^{2}$ Y. Kadooka, ${ }^{2}$ and M. Sato ${ }^{1} \dagger$ \\ ${ }^{1}$ Laboratory of Nutrition Chemistry, Department of Bioscience and Biotechnology, Faculty of Agriculture, Graduate School, Kyushu University, \\ 744 Motooka, Nishi-ku, Fukuoka 819-0395, Japan \\ ${ }^{2}$ Milk Science Research Institute, Megmilk Snow Brand Co., Ltd., 1-1-2 Minamidai, Kawagoe, Saitama 350-1165, Japan
}

\section{ABSTRACT}

The probiotic Lactobacillus gasseri SBT2055 (LG2055) has a protective effect against metabolic syndrome in rats and humans. Metabolic syndrome increases the risk of type 2 diabetes mellitus. In this study, Goto-Kakizaki rats were used as a diabetic model and fed diets containing LG2055-fermented or nonfermented skim milk for 4 wk. Indices of diabetes such as blood glucose levels, serum glucagon levels, plasma levels of insulin, C-peptide, and glucagon-like peptide-1, tissue glycogen contents, and pancreatic mRNA levels were measured. The plasma C-peptide levels and pancreatic mRNA levels of insulin genes (Ins1 and Ins2) and $P d x 1$ (a transcriptional factor of insulin genes) were increased in LG2055 diet-fed rats. The increase in insulin secretion corresponded to an improvement in serum and pancreatic inflammatory status, associated with decreases in serum levels of serum amyloid P and pancreatic levels of granulocyte colony-stimulating factor. Insulin resistance in Goto-Kakizaki rats was ameliorated by increased glycogen storage in the liver and quadriceps femoris muscles and decreased serum free fatty acid levels. This improvement may be related to the increased cecal production of short-chain fatty acids. In conclusion, dietary LG2055 improved insulin secretion in diabetic rats by improving the inflammatory status in the pancreas and serum.

Key words: Lactobacillus gasseri SBT2055, insulin secretion, inflammation, diabetes

\section{INTRODUCTION}

The use of probiotic strains is increasing because they can exert beneficial effects by altering the gut flora (Markowiak and Śliżewska, 2017). Lactobacillus gasseri

Received June 13, 2018.

Accepted September 18, 2018.

*These authors contributed equally to the study.

†Corresponding author: masaos@agr.kyushu-u.ac.jp
SBT2055 (LG2055) is a probiotic lactic acid bacterium of human origin, which has been found to improve the intestinal microflora and lipid metabolism, reduce postprandial lipid absorption, and exert anti-obesity effects in rats and humans (Sato et al., 2008; Kadooka et al., 2010; Ogawa et al., 2014). A meta-analysis (John et al., 2018) of human intervention studies on the effects of probiotics on obesity revealed that the modulation of the gut microbiome is essential for preventing obesity and can substantially decrease obesity outcomes. This meta-analysis included a series of 2 intervention studies using LG2055 (Kadooka et al., 2010, 2013). The intake of LG2055 enhanced energy expenditure via carbohydrate oxidation, improved glucose tolerance, and attenuated inflammation in rats (Shirouchi et al., 2016). In mice fed a high-fat diet, the intake of LG2055 inhibited the translocation of LPS to decrease inflammation in adipose tissues (Kawano et al., 2016).

The main advantage of probiotics is that they can reduce gastrointestinal tract inflammation by changing the intestinal microflora and attenuating associated pathological conditions. In a healthy intestine, the translocation of LPS from the gut lumen into the blood circulatory system is prevented by the intestinal barrier. The translocation of LPS into the circulation due to the disruption of intestinal barrier function could trigger inflammation, leading to the development of various diseases such as obesity (von Scholten et al., 2013), nonalcoholic fatty liver (Soares et al., 2010), atherosclerosis (Wiesner et al., 2010), and diabetes (Creely et al., 2007). Therefore, the onset of these diseases may be suppressed by decreasing the concentration of LPS in the blood. A meta-analysis of human intervention studies assessing the effects of probiotics on dyslipidemia, which causes arteriosclerosis, has been conducted (He et al., 2017). Human intervention studies (Firouzi et al., 2017) and a meta-analysis (Yao et al., 2017) of inhibiting diabetes onset by probiotics have also been performed. The meta-analyses of fasting glucose levels, hemoglobin A1c, fasting insulin levels, and homeostatic model assessment of insulin resistance (diabetes out- 
comes) revealed that probiotics reduced all outcomes (Yao et al., 2017). Furthermore, C-reactive protein (CRP) levels were the most effectively reduced by probiotics. In other words, the main effect of probiotics on diabetes is the suppression of inflammation, as demonstrated by the decrease in serum CRP levels with reduced diabetes outcomes.

Goto-Kakizaki (GK) rats, an animal model of spontaneous nonobese type 2 diabetes, have been produced by selective breeding of normal Wistar rats using glucose tolerance as the selection index (Goto et al., 1988). Goto-Kakizaki rats have decreased $\beta$-cell numbers and function accompanied by mild hyperglycemia, impaired insulin secretion, and peripheral insulin resistance (Bisbis et al., 1993; O'Rourke et al., 1997; Ueta et al., 2005; Movassat et al., 2008; Portha et al., 2009). In addition, GK rats exhibit inflammation in the pancreatic islets (Homo-Delarche et al., 2006), liver (Almon et al., 2009), and peripheral tissues such as adipose tissues (Xue et al., 2011).

In the present study, we investigated the effects of LG2055 intake on insulin secretion using GK rats. In addition, we measured the serum levels of serum amyloid P (SAP; an acute-phase reactant) using an ELISA, and the levels of serum and pancreatic cytokines using a multiple cytokine assay with magnetic bead antibodies.

\section{MATERIALS AND METHODS}

\section{Preparation of Milk Fermented by LG2055}

Milk fermented by LG2055 was prepared as described previously (Shirouchi et al., 2016). In addition, the chemical compositions of skim milk (SM) and LG2055 fermented SM powders were the same as described previously (Shirouchi et al., 2016). The final concentration of viable LG2055 in the fermented SM-containing diet was $6 \times 10^{7} \mathrm{cfu} / \mathrm{g}$ of diet.

\section{Animal Experiments}

Four-week-old male GK rats were obtained from Japan SLC Inc. (Shizuoka, Japan). The rats were housed individually in metal cages in a temperaturecontrolled room $\left(21-23^{\circ} \mathrm{C}\right)$ with a 12 -h light, 12 -h dark cycle. Experimental diets were prepared based on the AIN-76 formula (American Institute of Nutrition, 1977) with several modifications and contained $(\mathrm{g} / \mathrm{kg}) 100$ fat (90 lard and 10 corn oil), 200 nonfermented SM powder (control diet) or LG2055-fermented SM powder (LG2055 diet), 125 casein, 150 a-cornstarch, 50 cellulose, 3 DL-methionine, 35 mineral mixture (AIN-76), 10 vitamin mixture (AIN-76), 0.5 cholesterol, and 326.5 sucrose. The protein concentration of diets prepared using fermented and nonfermented SM was the same as described previously (Shirouchi et al., 2016). Diets containing high sucrose levels and lard rich in SFA were used to induce obesity and glucose intolerance. The rats were allowed free access to commercial chow for a week and were subsequently divided into the control and LG2055 groups ( $\mathrm{n}=8$ /group). There was no major difference in the initial BW between the 2 groups (control group, $113 \pm 2 \mathrm{~g}$; LG2055 group, $114 \pm 2 \mathrm{~g}$ ). The experimental diets were pair-fed to the rats for $4 \mathrm{wk}$ to avoid effects of the differences in food intake and calorie between the group on inflammatory status. After 3 wk, an oral glucose tolerance test was performed. At the end of the feeding period, the animals were subjected to a 9-h fasting period, anesthetized with Somnopentyl (Kyouritsu Seiyaku Corporation, Tokyo, Japan), and killed by withdrawing blood from the abdominal aorta. The liver, white adipose tissues (mesenteric, perirenal, retroperitoneal, epididymal, and subcutaneous), quadriceps femoris, femur, pancreas, and cecum were immediately excised and weighed. Collected blood was immediately divided for preparation of plasma and serum. The EDTA-containing plasma was prepared by blood centrifugation at $1,750 \times g$ for $15 \mathrm{~min}$, and a DPP-IV inhibitor (EMD Millipore Co., St. Charles, MO) was added to measure glucagon-like peptide-1 (GLP-1) levels. The serum was separated by incubating blood samples for $30 \mathrm{~min}$ at room temperature. The samples were kept at $-30^{\circ} \mathrm{C}$ until analysis. All animal experiments were conducted according to the Guidelines for Animal Experiments of Kyushu University as well as Law No. 105 and Notification No. 6 of the Ministry of the Environment (1973). Animal protocols were approved by the review committees of Kyushu University (authorization no. A26-098-3).

\section{Oral Glucose Tolerance Test}

After 3 wk of feeding, the rats were subjected to 16 $\mathrm{h}$ of fasting followed by oral administration of a glucose bolus $(2 \mathrm{~g} / \mathrm{kg}$ of BW). Blood was drawn from the tail vein at $0,15,30,60,90,120,150,180,240,300$, and 360 min after bolus administration, and glucose levels were measured using an Accu-Chek Aviva Nano blood glucose meter (Roche Diagnostics, Tokyo, Japan). The area under the curve (AUC) of blood glucose concentration (0-360 min) was calculated using the trapezoidal rule.

\section{Analysis of Metabolic Variables}

Serum levels of triacylglycerol, cholesterol, free fatty acids, and glucose were measured using enzyme assay 
kits (Triglyceride E-Test, Cholesterol E-Test, NEFA C-Test, and Glucose CII-Test, respectively; Wako Pure Chemicals, Tokyo, Japan). For measurement of serum high-density lipoprotein (HDL) cholesterol levels, serum and a working reagent containing $10 \mathrm{~g} / \mathrm{L}$ dextran sulfate, $71.1 \mathrm{~g} / \mathrm{L} \mathrm{MgCl}_{2}$, and $0.5 \mathrm{~g} / \mathrm{L}$ sodium azide were mixed at a ratio of 10 volumes of specimen to 1 volume of reagent. The samples were incubated at room temperature for $10 \mathrm{~min}$, and then centrifuged at 1,750 $\times$ $g$ for $10 \mathrm{~min}$ at $4^{\circ} \mathrm{C}$, and $\mathrm{HDL}$ cholesterol levels in the supernatant were measured using the enzyme assay kit (Cholesterol E-Test). Serum non-HDL cholesterol levels were calculated as the difference between cholesterol and HDL cholesterol levels. Plasma levels of C-peptide, insulin, and GLP-1, and serum levels of glucagon and SAP were measured using commercial ELISA kits (Rat C-peptide ELISA Kit and Rat Insulin ELISA Kit from Shibayagi Co., Ltd., Gunma, Japan; Rat GLP-1 ELISA Kit and Rat Glucagon ELISA Kit from Wako Pure Chemicals; Serum Amyloid P Rat ELISA Kit from Abcam, Tokyo, Japan). Glycogen levels in the liver and muscles were determined according to the method of Lo et al. (1970). Liver lipids were extracted according to the method of Folch et al. (1957). Liver triacylglycerol levels were measured using the Triglyceride E-Test assay kit. Liver total and free cholesterol levels were measured as described by Sperry and Webb (1950).

\section{Analysis of Mucin, Lactic Acid, and Short-Chain Fatty Acid Levels in the Cecum and Serum}

Cecal mucin contents were measured using the Fecal Mucin Assay Kit (Cosmo Bio Co., Ltd., Tokyo, Japan). Cecal lactic acid and short-chain fatty acid (SCFA) levels were determined as described previously (Shirouchi et al., 2016). The total SCFA content in the cecum is the sum of acetate, propionate, and butyrate contents.

Serum SCFA levels (acetate, propionate, isobutyrate, butyrate, isovalerate, and valerate) were measured as described previously (Zheng et al., 2013) with several modification. In brief, the samples were derivatized with propyl chloroformate and analyzed by GC-MS. The GCMS was performed using a Shimadzu GCMS-QP2020 spectrometer (Shimadzu, Tokyo, Japan) equipped with a capillary column (InertCap 5MS/NP-VS2, $0.25 \mathrm{~mm}$ i.d. $\times 30 \mathrm{~m}, \mathrm{df}=0.25 \mu \mathrm{m}$; GL Sciences Inc., Tokyo, Japan). The following temperature program was applied with helium (high-purity, 99.9999\%) as a carrier gas at a flow rate of $1.0 \mathrm{~mL} / \mathrm{min}: 50^{\circ} \mathrm{C}$ for $2 \mathrm{~min}$; from 50 to $70^{\circ} \mathrm{C}$ at $10^{\circ} \mathrm{C} / \mathrm{min}$; from 70 to $85^{\circ} \mathrm{C}$ at $3^{\circ} \mathrm{C} / \mathrm{min}$; from 85 to $110^{\circ} \mathrm{C}$ at $5^{\circ} \mathrm{C} / \mathrm{min}$; from 110 to $290^{\circ} \mathrm{C}$ at $30^{\circ} \mathrm{C} /$ $\mathrm{min} ; 290^{\circ} \mathrm{C}$ for $8 \mathrm{~min}$. The temperature of the front inlet, transfer line, and electron impact ion source was set at 230,290 , and $200^{\circ} \mathrm{C}$, respectively. The ionization voltage was $70 \mathrm{~V}$, and mass spectral data were collected in the scan mode $(\mathrm{m} / \mathrm{z} 30-600)$.

\section{Determination of Pancreatic mRNA Levels}

Total cellular RNA was isolated from pancreatic tissues using a guanidinium thiocyanate-cesium chloride ultracentrifugation method (Chirgwin et al., 1979). The cDNA was synthesized from $1.0 \mu \mathrm{g}$ of total RNA using Transcriptor First Strand cDNA Synthesis Kit (Roche, Berlin, Germany). The expression levels for 7 genes associated with glucose metabolism were analyzed by quantitative real-time reverse transcription PCR using a SYBR Premix EX TaqII kit with Thermal Cycler Dice Real Time System TP800 (Takara, Shiga, Japan). The mRNA levels were normalized using Actb as a housekeeping gene. The sequences of the oligonucleotides were as follows: Ins1 forward (TCAGGTCATCACTATCGGCA) and reverse (TCATGGATGCCACAGGATTC), Ins2 forward (ATCCTCTGGGAGCCCCGC) and reverse (CTTGGTGGAAGCTCTCT), Sod1 forward (AGAGGCATGTTGGAGACCTGG) and reverse (CGGCCAATGATGGAATGCT), Cat forward (CATGAATGGCTATGGCTCACAC) and reverse (CAACAGGCAAGTTTTTGATGCC), Hmox1 forward (CAGAAGGGYCAGGTGTCCAG) and reverse (GAAGGCCATGTCCTGCTCTA), Pdx1 forward (GGATGAAATCCACCAAAGCTC) and reverse (TTCCACTTCATGCGACGGT), ccnd2 forward (CAAGATCACCCACACCGATG) and reverse (GTCAACATCCCGCACGTCTG), and Actb forward (TCAGGTCATCACTATCGGCA) and reverse (TCATGGATGCCACAGGATTC).

\section{Determination of Serum and Pancreatic Cytokine Levels}

To evaluate cytokine contents in the pancreas, a piece of tissue was homogenized in ice-cold PBS buffer containing protease inhibitors (Protease Inhibitor Cocktail; Sigma-Aldrich, Tokyo, Japan). The homogenate was centrifuged at $10,000 \times g$ for $30 \mathrm{~min}$ at $4^{\circ} \mathrm{C}$, and the supernatant was used for cytokine analysis. The serum and pancreatic levels of epidermal growth factor, eotaxin, fractalkine, granulocyte colonystimulating factor (G-CSF), granulocyte-macrophage colony-stimulating factor (GM-CSF), growth-related oncogene/keratinocyte chemoattractant (GRO/KC; systemic name: CXCL1), IFN $\gamma$, IL-10, IL-12 (p70), IL13, IL-17, IL-18, IL-1 $\alpha$, IL-1 $\beta$, IL-2, IL-4, IL-5, IL-6, IFN $\gamma$-induced protein-10 (IP-10), LPS-induced C-XC motif chemokine (LIX; systemic name: CXCL5), leptin, monocyte chemoattractant protein-1 (MCP-1), 
macrophage inflammatory protein (MIP)-1 $\alpha$, MIP-2, regulated on activation, normal $\mathrm{T}$ cell expressed and secreted (RANTES), tumor necrosis factor- $\alpha$ (TNF- $\alpha$ ), and vascular endothelial growth factor (VEGF) were measured with the Milliplex MAP Rat Cytokine/Chemokine Magnetic Bead Panel kit (EMD Millipore Corp., Billerica, MA) using the Luminex MAGPIX System with Milliplex Analyst Software (Millipore) according to the manufacturer's instructions. Pancreatic protein levels were measured using Quick Start Bradford Protein Assay (Bio-Rad, Hercules, CA) with BSA as the standard. Pancreatic cytokine levels were normalized to the protein level.

\section{Determination of Pancreatic Oxidative \\ Stress Markers}

Pancreatic superoxide dismutase (SOD) activity was measured using a SOD assay kit (Dojindo Molecular Technologies, Kumamoto, Japan). Pancreatic levels of $\mathrm{NAD}$ and $\mathrm{NADH}$ were measured using $\mathrm{NAD} / \mathrm{NADH}$ Quantitation Colorimetric Kit (BioVision, Milpitas, CA). Pancreatic protein levels were measured using Quick Start Bradford Protein Assay (Bio-Rad) with BSA as the standard. Pancreatic cytokine levels were normalized to the protein level.

\section{Statistical Analysis}

All values are expressed as the mean \pm standard error of the mean. Differences between the 2 groups were determined by Student's $t$-test and were considered statistically significant at $P<0.05$.

\section{RESULTS}

\section{Effects of the LG2055 Diet on Postprandial Glucose Responses}

The oral glucose tolerance test revealed no large differences in postprandial glucose levels and glucose AUC levels between the 2 groups (Figure 1 ).

\section{Effects of the LG2055 Diet on Metabolic Variables}

The effects of the control and LG2055 diets on morphometric and metabolic variables are shown in Table 1. The 2 groups of rats did not differ in their food intake and total water intake after a 4 -wk feeding period. Although food efficiency was lower $(P<0.05)$ in LG2055 diet-fed rats, the LG2055 diet did not affect organ weights (liver, pancreas, cecum, quadriceps femoris, femur, and white adipose tissues). Moreover, the levels of serum lipids (triacylglycerol, cholesterol, non-
HDL cholesterol, and phospholipids) and liver lipids (triacylglycerol, total cholesterol, and free cholesterol) were not considerably different between the 2 groups. On the other hand, serum HDL cholesterol levels were increased $(P<0.05)$, whereas serum free fatty acid levels were decreased in LG2055 diet-fed rats. As shown in Figure 2A-2D, following $9 \mathrm{~h}$ of fasting, serum levels of glucose and glucagon as well as plasma levels of GLP1 and insulin were not considerably different between the 2 groups. On the other hand, plasma C-peptide and liver glycogen levels were increased $(P<0.05)$ in LG2055 diet-fed rats, and quadriceps femoris glycogen levels tended to be higher $(P=0.096)$ in the LG2055 group (Figure $2 \mathrm{E}-2 \mathrm{G}$ ).

\section{Effects of the LG2055 Diet on Cecal Lactic Acid and SCFA Concentration}

As shown in Table 2, cecal weights, $\mathrm{pH}$, and contents [propionate, n-butyrate, (L)-lactate, and mucin] did not differ between the 2 groups. However, the concentration of cecal acetate was higher $(P<0.05)$ in LG2055 diet-fed rats, which contributed to the marked increase in the total SCFA content in the cecum. In addition, except for valeric acid, serum SCFA levels did not differ between the 2 groups.

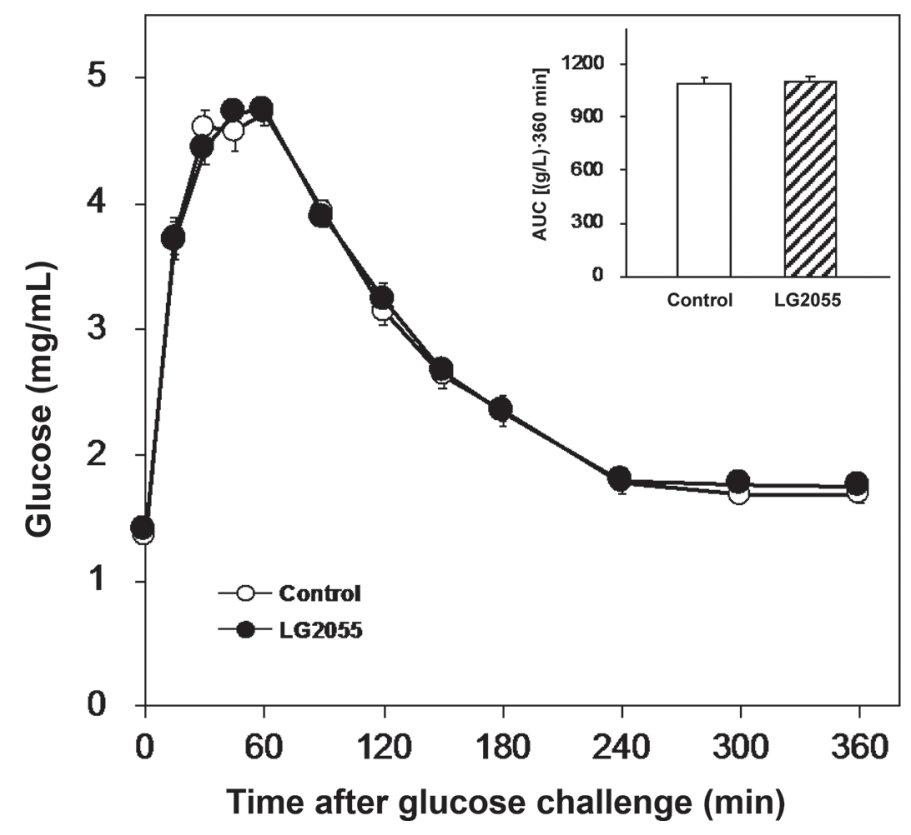

Figure 1. Glucose tolerance in Goto-Kakizaki (GK) rats fed the control diet or Lactobacillus gasseri SBT2055 (LG2055) diet for 3 wk. Blood glucose levels were determined after $16 \mathrm{~h}$ of fasting. Following oral glucose administration, blood glucose levels were measured at the indicated intervals. The inset shows the area under the curve (AUC) for each group. Values are the means with SEM ( $\mathrm{n}=8$ /group). 


\section{Effects of the LG2055 Diet on Serum and Pancreatic Cytokine Levels}

Table 3 shows the serum cytokine levels of GK rats fed the LG2055 diet. In the present study, epidermal growth factor, GM-CSF, GRO/KC, IFN $\gamma$, IL-2, and IL-6 were not detected in serum of rats because their concentrations were less than the minimum detectable concentrations. No marked differences were present in the serum levels of leptin, MCP-1, RANTES, GCSF, IL-4, IL-1 $\beta$, IL-13, IL-10, IL-12p70, IL-5, IL-17A, IP-10, VEGF, and MIP-2. The serum levels of SAP, TNF- $\alpha$, MIP- $1 \alpha$, and IL-18 were decreased $(P<0.05)$ in LG2055 diet-fed rats. The serum levels of fractalkine $(P=0.054)$, eotaxin $(P=0.074), \mathrm{IL}-1 \alpha(P=0.096)$, and LIX $(P=0.059)$ tended to be lower in LG2055 diet-fed rats.

Table 4 summarizes the pancreatic cytokine levels of GK rats fed the LG2055 diet. In the present study, epidermal growth factor, GM-CSF, IL-5, IL-13, IP-10, leptin, MCP-1, RANTES, TNF- $\alpha$, and VEGF were not detected in pancreas of rats because their concentrations were less than the minimum detectable concentrations. No substantial differences were present in IL-6, IFN $\gamma$, GRO/KC, eotaxin, IL-1 $\alpha$, MIP-1 $1 \alpha$, IL- 4, IL- $1 \beta$,
IL-2, IL-10, IL-17A, IL-18, fractalkine, LIX, and MIP-2 levels between the groups. The pancreatic levels of GCSF were reduced $(P<0.05)$ in LG2055 diet-fed rats. The pancreatic levels of IL-12p70 tended to be lower $(P$ $=0.095)$ in LG2055 diet-fed rats.

\section{Effects of the LG2055 Diet on Pancreatic Oxidative Stress Markers}

As shown in Table 5, pancreatic oxidative stress markers such as SOD activity and the levels of NAD and NADH did not differ between the 2 groups.

\section{Effects of the LG2055 Diet on Pancreatic mRNA Levels}

Table 6 shows the mRNA expression of genes related to glucose metabolism in the pancreas. The pancreatic mRNA levels of Sod1, Cat, Hmox1, and Ccnd2 were not greatly different between the 2 groups. On the other hand, the pancreatic mRNA levels of insulin genes (Ins1 and Ins2) and $P d x 1$ (a transcriptional factor of insulin genes) were higher $(P<0.05)$ in the LG2055 group than in the control group.

Table 1. Morphometric and metabolic variables of Goto-Kakizaki rats fed the Lactobacillus gasseri SBT2055 (LG2055) diet $^{1}$

\begin{tabular}{|c|c|c|}
\hline Item & Control & LG2055 \\
\hline Initial BW (g) & $113 \pm 2$ & $114 \pm 2$ \\
\hline Final BW (g) & $232 \pm 4$ & $229 \pm 5$ \\
\hline Food intake $(\mathrm{g} / \mathrm{d})$ & $13.6 \pm 0.3$ & $13.6 \pm 0.3$ \\
\hline Food efficiency ( $\mathrm{g}$ of BW gain/g of food intake) & $0.312 \pm 0.002$ & $0.303 \pm 0.003^{*}$ \\
\hline Total water intake $(\mathrm{mL})$ & $603 \pm 29$ & $579 \pm 36$ \\
\hline \multicolumn{3}{|l|}{ Organ weight $(\mathrm{g})$} \\
\hline Liver & $8.37 \pm 0.15$ & $8.48 \pm 0.23$ \\
\hline Pancreas & $0.930 \pm 0.030$ & $0.900 \pm 0.020$ \\
\hline Cecum with contents & $2.09 \pm 0.08$ & $2.23 \pm 0.13$ \\
\hline Quadriceps femoris (right) & $1.28 \pm 0.06$ & $1.39 \pm 0.05$ \\
\hline Quadriceps femoris (left) & $1.42 \pm 0.06$ & $1.38 \pm 0.06$ \\
\hline Femur & $0.564 \pm 0.010$ & $0.560 \pm 0.010$ \\
\hline \multicolumn{3}{|l|}{ White adipose tissue $(\mathrm{g})$} \\
\hline Mesenteric & $2.97 \pm 0.15$ & $3.09 \pm 0.15$ \\
\hline Perirenal & $0.640 \pm 0.050$ & $0.650 \pm 0.050$ \\
\hline Retroperitoneal & $4.23 \pm 0.24$ & $4.10 \pm 0.18$ \\
\hline Epididymal & $2.84 \pm 0.08$ & $3.06 \pm 0.12$ \\
\hline Subcutaneous & $13.6 \pm 0.66$ & $14.1 \pm 0.67$ \\
\hline \multicolumn{3}{|l|}{ Serum lipid level } \\
\hline Triacylglycerol $(\mathrm{mg} / \mathrm{mL})$ & $0.847 \pm 0.117$ & $0.814 \pm 0.109$ \\
\hline Cholesterol $(\mathrm{mg} / \mathrm{mL})$ & $1.12 \pm 0.03$ & $1.16 \pm 0.04$ \\
\hline Phospholipids (mg/mL) & $1.94 \pm 0.06$ & $1.99 \pm 0.05$ \\
\hline HDL cholesterol (mg/mL) & $0.694 \pm 0.027$ & $0.877 \pm 0.066^{*}$ \\
\hline Non-HDL cholesterol (mg/mL) & $0.426 \pm 0.040$ & $0.280 \pm 0.078$ \\
\hline Free fatty acid $(\mathrm{Eq} / \mathrm{L})$ & $924 \pm 40$ & $780 \pm 29^{*}$ \\
\hline \multicolumn{3}{|l|}{ Liver lipid level (mg/g of liver) } \\
\hline Triacylglycerol & $9.20 \pm 0.52$ & $10.8 \pm 0.7$ \\
\hline Total cholesterol & $1.19 \pm 0.24$ & $1.53 \pm 0.21$ \\
\hline Free cholesterol & $0.93 \pm 0.13$ & $1.02 \pm 0.19$ \\
\hline
\end{tabular}

${ }^{1}$ Values are expressed as the mean \pm SEM ( $\mathrm{n}=8$ /group). HDL $=$ high-density lipoprotein.

*An asterisk indicates a difference at $P<0.05$. 
Table 2. Cecum characteristics and cecum and serum short-chain fatty acid (SCFA) levels of Goto-Kakizaki rats fed the Lactobacillus gasseri SBT2055 (LG2055) diet ${ }^{1}$

\begin{tabular}{lcc}
\hline Item & Control & LG2055 \\
\hline Cecum weight $(\mathrm{g})$ & $2.08 \pm 0.08$ & $2.12 \pm 0.12$ \\
Cecum content weight $(\mathrm{g})$ & $1.51 \pm 0.07$ & $1.58 \pm 0.11$ \\
Cecum wall $(\mathrm{g})$ & $0.559 \pm 0.014$ & $0.528 \pm 0.026$ \\
Cecum pH & $7.93 \pm 0.17$ & $8.08 \pm 0.03$ \\
Cecum SCFA ( $\mu \mathrm{mol} / \mathrm{g}$ of content) & $30.4 \pm 0.9$ & $35.4 \pm 1.9^{*}$ \\
Acetate & $9.21 \pm 0.35$ & $9.35 \pm 0.34$ \\
Propionate & $3.17 \pm 0.45$ & $3.65 \pm 0.31$ \\
n-Butyrate & $2.56 \pm 0.26$ & $2.75 \pm 0.25$ \\
(L)-Lactate & $42.7 \pm 1.1$ & $48.4 \pm 2.0^{*}$ \\
Total & $0.391 \pm 0.08$ & $0.341 \pm 0.04$ \\
Cecum mucin content $(\mathrm{mg} / \mathrm{g}$ of content) & & \\
Serum SCFA $(\mu \mathrm{g} / \mathrm{mL})$ & $29.7 \pm 1.5$ & $29.3 \pm 1.3$ \\
Acetate & $48.7 \pm 5.2$ & $50.8 \pm 4.3$ \\
Propionate & $0.807 \pm 0.075$ & $0.826 \pm 0.040$ \\
n-Butyrate & $0.0236 \pm 0.0025$ & $0.0150 \pm 0.0021^{*}$ \\
Valerate & $78.7 \pm 6.3$ & $80.5 \pm 5.2$ \\
Total & & \\
Serum branched SCFA $(\mu \mathrm{g} / \mathrm{mL})$ & $0.320 \pm 0.026$ & $0.336 \pm 0.020$ \\
Isobutyrate & $1.27 \pm 0.12$ & $1.34 \pm 0.09$ \\
Isovalerate & $2.07 \pm 0.19$ & $2.17 \pm 0.12$ \\
Total & &
\end{tabular}

${ }^{1}$ Values are expressed as the mean \pm SEM $(\mathrm{n}=8$ /group).

*An asterisk indicates a difference at $P<0.05$.

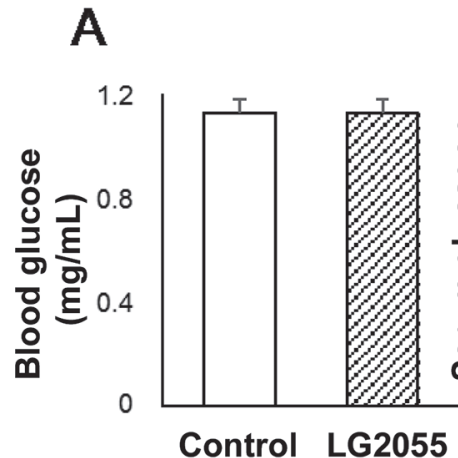

B

C
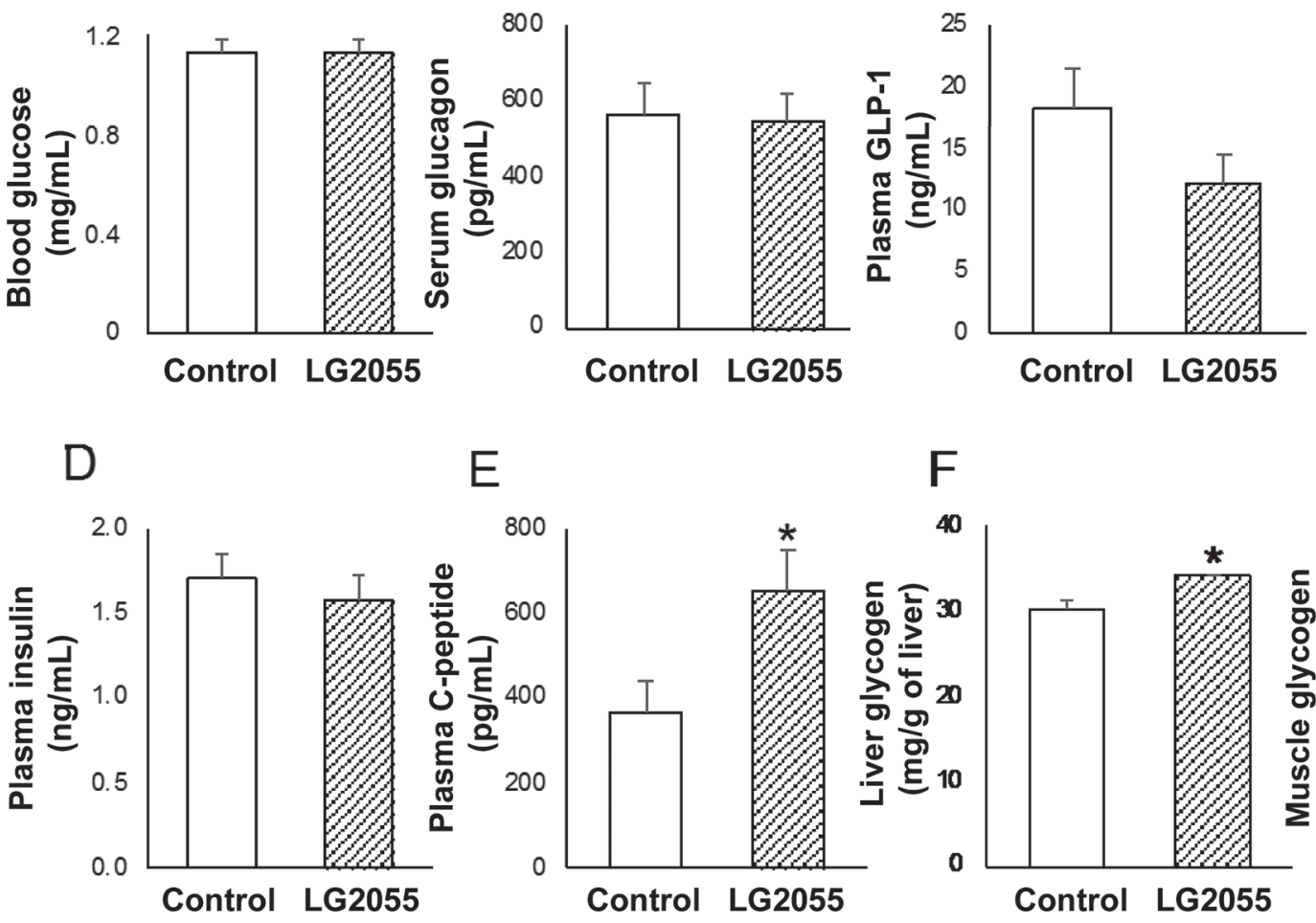

G

Figure 2. (A) Blood glucose levels; (B) serum glucagon levels; plasma levels of (C) glucagon-like peptide-1 (GLP-1), (D) insulin, and (E) C-peptide; and glycogen contents in the (F) liver and (G) muscles (quadriceps femoris) of Goto-Kakizaki rats fed the control diet or Lactobacillus gasseri SBT2055 (LG2055) diet for 4 wk. The variables were measured after $9 \mathrm{~h}$ of fasting. Values are the means with SEM (n $=8 /$ group). $*$ An asterisk indicates mean values different from those of the control group at $P<0.05$. 
Table 3. Serum cytokine levels of Goto-Kakizaki rats fed the Lactobacillus gasseri SBT2055 (LG2055) $\operatorname{diet}^{1}$

\begin{tabular}{|c|c|c|}
\hline Item & Control & LG2055 \\
\hline \multicolumn{3}{|l|}{$(\mu \mathrm{g} / \mathrm{mL})$} \\
\hline $\begin{array}{l}\text { SAP } \\
(\mathrm{ng} / \mathrm{mL})\end{array}$ & $328 \pm 14$ & $295 \pm 4^{*}$ \\
\hline Leptin & $27.0 \pm 1.6$ & $26.0 \pm 2.8$ \\
\hline LIX & $5.91 \pm 0.42$ & $4.76 \pm 0.37(P=0.059)$ \\
\hline MCP-1 & $1.07 \pm 0.1$ & $0.92 \pm 0.09$ \\
\hline RANTES & $4.53 \pm 0.29$ & $3.90 \pm 0.27$ \\
\hline \multicolumn{3}{|l|}{$(\mathrm{pg} / \mathrm{mL})$} \\
\hline TNF- $\alpha$ & $4.55 \pm 0.36$ & $3.45 \pm 0.19^{*}$ \\
\hline MIP- $1 \alpha$ & $31.9 \pm 2.3$ & $23.4 \pm 2.5^{*}$ \\
\hline IL-18 & $166 \pm 16$ & $100 \pm 19^{*}$ \\
\hline Fractalkine & $142 \pm 9$ & $107 \pm 14(P=0.054)$ \\
\hline Eotaxin & $18.7 \pm 1.4$ & $15.8 \pm 0.6(P=0.074)$ \\
\hline IL- $1 \alpha$ & $50.9 \pm 7.1$ & $33.7 \pm 6.3(P=0.096)$ \\
\hline G-CSF & $14.5 \pm 3.1$ & $10.8 \pm 1.4$ \\
\hline IL-4 & $33.7 \pm 3.5$ & $30.7 \pm 1.4$ \\
\hline IL-1 $\beta$ & $50.3 \pm 7.3$ & $95.9 \pm 39.6$ \\
\hline IL-13 & $19.2 \pm 2.4$ & $16.0 \pm 1.3$ \\
\hline IL-10 & $37.4 \pm 5.0$ & $56.7 \pm 16.6$ \\
\hline IL-12p70 & $254 \pm 42$ & $280 \pm 22$ \\
\hline IL-5 & $76.4 \pm 4.8$ & $72.1 \pm 1.8$ \\
\hline IL-17A & $17.8 \pm 2.3$ & $14.2 \pm 1.8$ \\
\hline IP-10 & $368 \pm 16$ & $346 \pm 17$ \\
\hline VEGF & $41.8 \pm 5.8$ & $31.3 \pm 3.9$ \\
\hline MIP-2 & $104 \pm 21$ & $76.1 \pm 10.8$ \\
\hline
\end{tabular}

${ }^{1}$ Values are expressed as the mean \pm SEM ( $\mathrm{n}=8$ /group). G-CSF $=$ granulocyte colony-stimulating factor; IP-10 $=$ IFN $\gamma$-induced protein-10; LIX = LPS-induced C-X-C motif chemokine; $\mathrm{MCP}=$ monocyte chemoattractant protein; MIP = macrophage inflammatory protein; RANTES $=$ regulated on activation $=$ normal $\mathrm{T}$ cell expressed and secreted; $\mathrm{SAP}=$ serum amyloid $\mathrm{P} ; \mathrm{TNF}=$ tumor necrosis factor; VEGF $=$ vascular endothelial growth factor

*An asterisk indicates a difference at $P<0.05$.

Table 4. Pancreatic cytokine levels of Goto-Kakizaki rats fed the Lactobacillus gasseri SBT2055 (LG2055) diet ${ }^{1}$

\begin{tabular}{|c|c|c|}
\hline Item & Control & LG2055 \\
\hline IL-6 $(\mu \mathrm{g} / \mathrm{mg}$ of protein $)$ & $2.48 \pm 0.54$ & $2.06 \pm 0.49$ \\
\hline $\operatorname{IFN} \gamma(\mu \mathrm{g} / \mathrm{mg}$ of protein $)$ & $5.86 \pm 0.18$ & $5.71 \pm 0.35$ \\
\hline $\begin{array}{l}\mathrm{GRO} / \mathrm{KC}(\mu \mathrm{g} / \mathrm{mg} \text { of protein) } \\
(\mathrm{pg} / \mathrm{mg} \text { of protein) }\end{array}$ & $3.30 \pm 0.35$ & $3.21 \pm 0.33$ \\
\hline G-CSF & $110 \pm 19$ & $50.2 \pm 9.9^{*}$ \\
\hline IL-12p70 & $844 \pm 216$ & $442 \pm 81(P=0.095)$ \\
\hline Eotaxin & $114 \pm 19$ & $97.6 \pm 16.6$ \\
\hline IL-1 $\alpha$ & $273 \pm 42$ & $233 \pm 27$ \\
\hline MIP-1 $1 \alpha$ & $23.4 \pm 5.2$ & $17.7 \pm 4.2$ \\
\hline IL-4 & $284 \pm 54$ & $192 \pm 37$ \\
\hline IL-1 $\beta$ & $365 \pm 55$ & $333 \pm 48$ \\
\hline IL-2 & $241 \pm 74$ & $223 \pm 45$ \\
\hline IL-10 & $431 \pm 51$ & $351 \pm 49$ \\
\hline IL-17A & $103 \pm 16$ & $71.5 \pm 14.7$ \\
\hline IL-18 & $339 \pm 53$ & $483 \pm 119$ \\
\hline Fractalkine & $86.3 \pm 13.1$ & $86.8 \pm 12.0$ \\
\hline LIX & $402 \pm 51$ & $415 \pm 61$ \\
\hline MIP-2 & $390 \pm 51$ & $368 \pm 84$ \\
\hline
\end{tabular}

${ }^{1}$ Values are expressed as the mean \pm SEM ( $\mathrm{n}=8$ /group). G-CSF $=$ granulocyte colony-stimulating factor; $\mathrm{GRO} / \mathrm{KC}=$ growth-related oncogene/keratinocyte chemoattractant; LIX = LPS-induced C-X-C motif chemokine; MIP = macrophage inflammatory protein.

*An asterisk indicates a difference at $P<0.05$.
Table 5. Pancreatic oxidative stress markers of Goto-Kakizaki rats fed the Lactobacillus gasseri SBT2055 (LG2055) $\operatorname{diet}^{1}$

\begin{tabular}{lll}
\hline Item & \multicolumn{1}{c}{ Control } & \multicolumn{1}{c}{ LG2055 } \\
\hline NADH (pmol/mg of protein) & $9.46 \pm 1.15$ & $7.80 \pm 0.78$ \\
NAD (pmol/mg of protein) & $26.3 \pm 4.9$ & $27.3 \pm 5.5$ \\
NAD/NADH & $3.76 \pm 0.68$ & $3.77 \pm 0.90$ \\
SOD activity (unit/g of pancreas) & $3.53 \pm 0.09$ & $3.64 \pm 0.12$ \\
\hline
\end{tabular}

${ }^{1}$ Values are expressed as the mean \pm SEM $(\mathrm{n}=8$ /group). SOD $=$ superoxide dismutase.

\section{DISCUSSION}

As a probiotic, dietary LG2055 enhanced insulin secretion from the pancreas of GK diabetic rats in this study. The increased secretion of insulin led to an increase in liver and muscle glycogen levels (Figure 1). Goto-Kakizaki rats represent insulin hyposecretion after glucose loading (Goto et al., 1988). In this study, no differences were observed in the hematic indices of diabetes (postprandial blood glucose responses and glucose AUC levels) between the 2 groups (Figure 1). However, in a previous study using nondiabetic rats [Sprague-Dawley (SD) rats] fed the LG2055 diet, the glucose AUC levels were decreased by $20 \%$ following LG2055 intake (Shirouchi et al., 2016). Furthermore, the glucose AUC levels of diabetic GK rats were higher than those of nondiabetic SD rats (Shirouchi et al., 2016). Previous cross-sectional human studies have shown that insulin resistance and type 2 diabetes are associated with higher levels of pro-inflammatory cytokines and acute-phase reactants such as CRP (Nilsson et al., 1998; Fröhlich et al., 2000). Serum amyloid P is an acute-phase protein in systemic inflammation, which shares approximately $60 \%$ homology with CRP (de Beer et al., 1982; Koenig, 2007), and it has comparable serum levels in rats and humans. Serum levels of SAP are increased in response to serum LPS levels. Kawano et al. (2016) reported that in mice fed the LG2055 diet, serum levels of anti-LPS [Escherichia coli LPS (O111:B4)] IgG were decreased. Another study showed that serum levels of SAP were lower in SD rats

Table 6. Gene expression levels (arbitrary unit) in the pancreas of Goto-Kakizaki rats fed the Lactobacillus gasseri SBT2055 (LG2055) $\operatorname{diet}^{1}$

\begin{tabular}{lcc}
\hline Gene & Control & LG2055 \\
\hline Pdx1 & $1.00 \pm 0.31$ & $2.28 \pm 0.40^{*}$ \\
Ins1 & $1.00 \pm 0.07$ & $1.32 \pm 0.09^{*}$ \\
Ins2 & $1.00 \pm 0.05$ & $1.34 \pm 0.09^{*}$ \\
Sod1 & $1.00 \pm 0.05$ & $1.09 \pm 0.07$ \\
Cat & $1.00 \pm 0.11$ & $1.23 \pm 0.13$ \\
Hmox1 & $1.00 \pm 0.16$ & $0.96 \pm 0.18$ \\
Ccnd2 & $1.00 \pm 0.08$ & $1.07 \pm 0.08$ \\
\hline
\end{tabular}

${ }^{1}$ Values are expressed as the mean \pm SEM ( $\mathrm{n}=8$ /group).

*An asterisk indicates a difference at $P<0.05$. 
fed the LG2055 diet $(165 \pm 8 \mu \mathrm{g} / \mathrm{mL})$ than in $\mathrm{SD}$ rats fed the control diet $(192 \pm 6 \mu \mathrm{g} / \mathrm{mL}$; Shirouchi et al., 2016). In this study, serum levels of SAP were lower $(P<0.05)$ in GK rats fed the LG2055 diet $(295 \pm$ $4 \mu \mathrm{g} / \mathrm{mL}$ ) than in GK rats fed the control diet (328 $\pm 14 \mu \mathrm{g} / \mathrm{mL}$; Table 3). At higher SAP levels, a small decrease may not lead to an improvement in insulin resistance (an increase in glucose AUC levels; Figure 1). Goto-Kakizaki rats are more suitable than SD rats for inducing insulin hyposecretion because they exhibit abnormal glucose tolerance, which may be attributed to a perturbed pancreatic islet architecture (Zhang et al., 2002) and decreased $\beta$-cell numbers (Ihara et al., 1999). We observed that plasma C-peptide and pancreatic insulin mRNA levels were higher in diabetic rats fed the LG2055 diet than in the control rats. The AIN76-based diet used in this study contained higher levels of sucrose than starch. Therefore, the resulting antidiabetic effects may improve insulin secretion without altering the diabetic indices in diabetic rats.

Goto-Kakizaki rats have been reported to have lower insulin levels due to pancreatic functional defects (Zhang et al., 2002). Ihara et al. (1999) found that 8-hydroxy-2'-deoxyguanosine (8-OH dG) levels (a marker of DNA damage caused by reactive oxygen species) were increased in the pancreatic islets of GK rats. Therefore, we examined the radical status of LG2055 diet-fed rats. Several markers related to radical status were analyzed. Pancreatic NAD and NADH levels, $\mathrm{NAD} / \mathrm{NADH}$ ratio, and SOD activity were not different between the 2 diet groups (Table 5). In addition, Sod1, Cat, Hmox1, and Ccdn2 mRNA levels in the pancreas were not different between the groups (Table 6). However, inflammatory markers in the pancreas and whole body, pancreatic levels of G-CSF, and serum levels of SAP, TNF- $\alpha$, MIP- $\alpha$, and IL-18 were improved by dietary LG2055 (Tables 3 and 4). The G-CSF circulates in the bloodstream at low levels, but its levels are elevated accompanying the host response to infection or injury (Hamilton et al., 2016). Hamilton (2008) showed that G-CSF can be produced by many cell types upon addition of pro-inflammatory stimuli such as LPS in vitro. Therefore, the decrease in pancreatic G-CSF may be attributed to suppressed inflammation in the whole body, as demonstrated by the decrease in SAP levels in the serum (a systemic marker).

Production of SCFA by intestinal bacteria can be affected by changes in the intestinal flora (Ohira et al., 2017). In this study, the concentrations of acetate and total SCFA in the cecum were increased $(P<0.05)$; however, the $\mathrm{pH}$ of the cecum was not affected. As a result, the amount of mucin in the cecum was not affected (Table 2). A decrease in the $\mathrm{pH}$ of the cecum with an increase in SCFA production can cause the thickening of the mucosa and strengthen its barrier function (Sakata and Setoyama, 1995; Barcelo et al., 2000). It is possible that LG2055 does not strengthen the barrier function of the cecum, resulting in a decrease in the translocation of LPS into the blood. Han et al. (2017) showed that a high-fat diet could induce an alkaline shift in the cecal $\mathrm{pH}$ of rats. Our previous studies indicated that LG2055 could decrease lymphatic TAG absorption and increase fecal fatty acid excretion in rats (Hamad et al., 2009) and decrease postprandial TAG absorption in humans (Ogawa et al., 2014). Therefore, changes in the cecal SCFA profile need to be considered, including changes in the intestinal environment caused by an increase in unabsorbed dietary lipids in the cecum. In addition, Sedighi et al. (2017) reported a difference in the gut microbiota profiles of adult patients with type 2 diabetes and healthy individuals; the changes in dominant fecal bacterial genera found in type 2 diabetes patients highlight the link between type 2 diabetes and gut flora variation. The intake of LG2055 by SD rats without diabetes has been reported to increase the proportion of butyric acid in the cecum (Shirouchi et al., 2016). On the other hand, in this study, LG2055 intake by GK rats with diabetes resulted in an increase in cecal acetic acid and a decrease in serum valeric acid (Table 2). Therefore, the difference in SCFA dynamics may reflect the different gut flora of both rat strains.

Together with an improvement in inflammatory status, dietary LG2055 increased serum HDL cholesterol levels and decreased serum free fatty acid levels in GK rats (Table 1). Similarly, dietary LG2055 has been reported to decrease postprandial free fatty acid levels in a human intervention study (Ogawa et al., 2014). Inflammation can decrease HDL cholesterol levels and attenuate HDL functionality (Iqbal et al., 2017). On the other hand, HDL particles alone can improve the inflammatory status (Navab et al., 2011). The elevation of circulating free fatty acid levels induces inflammation in the skeletal muscles and liver through activation of nuclear factor-kappa B, resulting in the release of several inflammatory cytokines (Boden, 2006). Therefore, our results suggest that the improvement of serum lipid profiles by dietary LG2055 could contribute to an improvement in inflammatory status in the pancreas and serum of GK rats.

Our previous studies indicated that LG2055 reduced postprandial lipid absorption in rats and humans (Hamad et al., 2009; Ogawa et al., 2014). Additionally, previous studies showed that gut lactic acid bacteria produce unique fatty acids such as hydroxy, oxo, and conjugated fatty acids, which were derived from linoleic acid and $\alpha$-linolenic acid (Kishino et al., 2013; Hirata et al., 2015). Among unique fatty acids, $\alpha$-linolenic acidderived metabolites [13-hydroxy-9(Z),15(Z)-octadeca- 
dienoic acid and 13-oxo-9(Z),15(Z)-octadecadienoic acid] induce differentiation of anti-inflammatory M2type macrophages through $\mathrm{G}$ protein-coupled receptor 40 (Ohue-Kitano et al., 2018). Therefore, the antiinflammatory effects of LG2055 may contribute to the production of hydroxy and oxo fatty acids as well as SCFA in the gut.

\section{CONCLUSIONS}

Dietary LG2055 ameliorated insulin secretion via suppression of systemic inflammation and pancreatic inflammation in diabetic GK rats with insulin hyposecretion. Characterization of the active substances on anti-inflammation of LG2055 would be of interest for future study.

\section{ACKNOWLEDGMENTS}

The authors thank Editage (www.editage.jp) for English language editing. The study was supported by Megmilk Snow Brand Co., Ltd. (Saitama, Japan). M. N. and B.S. wrote the manuscript and contributed equally to the study. M. N., B. S., M. U., and Y. M. carried out the experimental work and collected and analyzed the data. B. S., A. O., F. S., Y. K., and M. S. contributed to the study design, supervised the study, and commented on the manuscript. All authors have read and approved the final version of the manuscript. A. O., F. S., and Y. K. are employees of Megmilk Snow Brand Co., Ltd. There are no other patents, products in development, or marketed products to declare. All other authors have no conflicts of interest to declare.

\section{REFERENCES}

Almon, R. R., D. C. DuBois, W. Lai, B. Xue, J. Nie, and W. J. Jusko. 2009. Gene expression analysis of hepatic roles in cause and development of diabetes in Goto-Kakizaki rats. J. Endocrinol. 200:331-346.

American Institute of Nutrition. 1977. Report of the American Institute of Nutrition ad hoc committee on standards for nutritional studies. J. Nutr. 107:1340-1348.

Barcelo, A., J. Claustre, F. Moro, J. A. Chayvialle, J. C. Cuber, and P. Plaisancié. 2000. Mucin secretion is modulated by luminal factors in the isolated vascularly perfused rat colon. Gut 46:218-224.

Bisbis, S., D. Bailbe, M. A. Tormo, F. Picarel-Blanchot, M. Derouet, J. Simon, and B. Portha. 1993. Insulin resistance in the GK rat: Decreased receptor number but normal kinase activity in liver. Am. J. Physiol. 265:E807-E813.

Boden, G. 2006. Fatty acid-induced inflammation and insulin resistance in skeletal muscle and liver. Curr. Diab. Rep. 6:177-181.

Chirgwin, J. M., A. E. Przybyla, R. J. MacDonald, and W. J. Rutter. 1979. Isolation of biologically active ribonucleic acid from sources enriched in ribonuclease. Biochemistry 18:5294-5299.

Creely, S. J., P. G. McTernan, C. M. Kusminski, F. M. Fisher, N. F. Da Silva, M. Khanolkar, M. Evans, A. L. Harte, and S. Kumar. 2007. Lipopolysaccharide activates an innate immune system response in human adipose tissue in obesity and type 2 diabetes. Am. J. Physiol. Endocrinol. Metab. 292:E740-E747. de Beer, F. C., M. L. Baltz, E. A. Munn, A. Feinstein, J. Taylor, C. Bruton, J. R. Clamp, and M. B. Pepys. 1982. Isolation and characterization of C-reactive protein and serum amyloid $\mathrm{P}$ component in the rat. Immunology 45:55-70.

Firouzi, S., H. A. Majid, A. Ismail, N. A. Kamaruddin, and M. Y. Barakatun-Nisak. 2017. Effect of multi-strain probiotics (multistrain microbial cell preparation) on glycemic control and other diabetes-related outcomes in people with type 2 diabetes: A randomized controlled trial. Eur. J. Nutr. 56:1535-1550.

Folch, J., M. Lees, and G. H. Sloane-Stanley. 1957. A simple method for the isolation and purification of total lipids from animal tissues. J. Biol. Chem. 226:497-509.

Fröhlich, M., A. Imhof, G. Berg, W. L. Hutchinson, M. B. Pepys, H. Boeing, R. Muche, H. Brenner, and W. Koenig. 2000. Association between C-reactive protein and features of the metabolic syndrome: A population-based study. Diabetes Care 23:1835-1839.

Goto, Y., K. Suzuki, T. Ono, M. Sasaki, and T. Toyota. 1988. Development of diabetes in the non-obese NIDDM rat (GK rat). Adv. Exp. Med. Biol. 246:29-31.

Hamad, E. M., M. Sato, K. Uzu, T. Yoshida, S. Higashi, H. Kawakami, Y. Kadooka, H. Matsuyama, I. A. Abd El-Gawad, and K. Imaizumi. 2009. Milk fermented by Lactobacillus gasseri SBT2055 influences adipocyte size via inhibition of dietary fat absorption in Zucker rats. Br. J. Nutr. 101:716-724.

Hamilton, J. A. 2008. Colony-stimulating factors in inflammation and autoimmunity. Nat. Rev. Immunol. 8:533-544.

Hamilton, J. A., A. D. Cook, and P. P. Tak. 2016. Anti-colony-stimulating factor therapies for inflammatory and autoimmune diseases. Nat. Rev. Drug Discov. 16:53-70.

Han, K. H., A. Yamamoto, K. I. Shimada, H. Kikuchi, and M. Fukushima. 2017. Dietary fat content modulates the hypolipidemic effect of dietary inulin in rats. Mol. Nutr. Food Res. 61:8. https:// doi.org/10.1002/mnfr.201600635.

He, J., F. Zhang, and Y. Han. 2017. Effect of probiotics on lipid profiles and blood pressure in patients with type 2 diabetes: A metaanalysis of RCTs. Medicine (Baltimore) 96:e9166.

Hirata, A., S. Kishino, S. B. Park, M. Takeuchi, N. Kitamura, and J. Ogawa. 2015. A novel unsaturated fatty acid hydratase toward C16 to C22 fatty acids from Lactobacillus acidophilus. J. Lipid Res. 56:1340-1350.

Homo-Delarche, F., S. Calderari, J. C. Irminger, M. N. Gangnerau, J. Coulaud, K. Rickenbach, M. Dolz, P. Halban, B. Portha, and P. Serradas. 2006. Islet inflammation and fibrosis in a spontaneous model of type 2 diabetes, the GK rat. Diabetes 55:1625-1633.

Ihara, Y., S. Toyokuni, K. Uchida, H. Odaka, T. Tanaka, H. Ikeda, H. Hiai, Y. Seino, and Y. Yamada. 1999. Hyperglycemia causes oxidative stress in pancreatic beta-cells of GK rats, a model of type 2 diabetes. Diabetes 48:927-932.

Iqbal, F., W. S. Baker, M. I. Khan, S. Thukuntla, K. H. McKinney, N. Abate, and D. Tuvdendorj. 2017. Current and future therapies for addressing the effects of inflammation on HDL cholesterol metabolism. Br. J. Pharmacol. 174:3986-4006.

John, G. K., L. Wang, J. Nanavati, C. Twose, R. Singh, and G. Mullin. 2018. Dietary alteration of the gut microbiome and its impact on weight and fat mass: A systematic review and meta-analysis. Genes (Basel) 9:E167.

Kadooka, Y., M. Sato, K. Imaizumi, A. Ogawa, K. Ikuyama, Y. Akai, M. Okano, M. Kagoshima, and T. Tsuchida. 2010. Regulation of abdominal adiposity by probiotics (Lactobacillus gasseri SBT2055) in adults with obese tendencies in a randomized controlled trial. Eur. J. Clin. Nutr. 64:636-643.

Kadooka, Y., M. Sato, A. Ogawa, M. Miyoshi, H. Uenishi, H. Ogawa, K. Ikuyama, M. Kagoshima, and T. Tsuchida. 2013. Effect of Lactobacillus gasseri SBT2055 in fermented milk on abdominal adiposity in adults in a randomised controlled trial. Br. J. Nutr. 110:1696-1703.

Kawano, M., M. Miyoshi, A. Ogawa, F. Sakai, and Y. Kadooka. 2016. Lactobacillus gasseri SBT2055 inhibits adipose tissue inflammation and intestinal permeability in mice fed a high-fat diet. J. Nutr. Sci. 5:e23. 
Kishino, S., M. Takeuchi, S. B. Park, A. Hirata, N. Kitamura, J. Kunisawa, H. Kiyono, R. Iwamoto, Y. Isobe, M. Arita, H. Arai, K. Ueda, J. Shima, S. Takahashi, K. Yokozeki, S. Shimizu, and J. Ogawa. 2013. Polyunsaturated fatty acid saturation by gut lactic acid bacteria affecting host lipid composition. Proc. Natl. Acad. Sci. USA 110:17808-17813.

Koenig, W. 2007. Serum amyloid P component and cardiovascular disease: Is there a sensible link? Arterioscler. Thromb. Vasc. Biol. 27:698-700.

Lo, S., J. C. Russell, and A. W. Taylor. 1970. Determination of glycogen in small tissue samples. J. Appl. Physiol. 28:234-236.

Markowiak, P., and K. Śliżewska. 2017. Effects of probiotics, prebiotics, and synbiotics on human health. Nutrients 9:1021.

Ministry of the Environment. 1973. Act on Welfare and Management of Animals in Japan. Accessed Nov. 9, 2018. http://www .japaneselawtranslation.go.jp/law/detail/ $? \mathrm{id}=61 \& \mathrm{vm}=04 \& \mathrm{re}=02$.

Movassat, J., D. Bailbé, C. Lubrano-Berthelier, F. Picarel-Blanchot, E. Bertin, J. Mourot, and B. Portha. 2008. Follow-up of GK rats during prediabetes highlights increased insulin action and fat deposition despite low insulin secretion. Am. J. Physiol. Endocrinol. Metab. 294:E168-E175.

Navab, M., S. T. Reddy, B. J. Van Lenten, and A. M. Fogelman. 2011 HDL and cardiovascular disease: Atherogenic and atheroprotective mechanisms. Nat. Rev. Cardiol. 8:222-232.

Nilsson, J., S. Jovinge, A. Niemann, R. Reneland, and H. Lithell. 1998. Relation between plasma tumor necrosis factor-alpha and insulin sensitivity in elderly men with non-insulin-dependent diabetes mellitus. Arterioscler. Thromb. Vasc. Biol. 18:1199-1202.

O'Rourke, C. M., J. A. Davis, A. R. Saltiel, and J. A. Cornicelli. 1997. Metabolic effects of troglitazone in the Goto-Kakizaki rat, a nonobese and normolipidemic rodent model of non-insulin-dependent diabetes mellitus. Metabolism 46:192-198.

Ogawa, A., Y. Kadooka, K. Kato, B. Shirouchi, and M. Sato. 2014 Lactobacillus gasseri SBT2055 reduces postprandial and fasting serum non-esterified fatty acid levels in Japanese hypertriacylglycerolemic subjects. Lipids Health Dis. 13:36.

Ohira, H., W. Tsutsui, and Y. Fujioka. 2017. Are short chain fatty acids in gut microbiota defensive players for inflammation and atherosclerosis? J. Atheroscler. Thromb. 24:660-672

Ohue-Kitano, R., Y. Yasuoka, T. Goto, N. Kitamura, S. B. Park, S. Kishino, I. Kimura, M. Kasubuchi, H. Takahashi, Y. Li, Y. S. Yeh, H. F. Jheng, M. Iwase, M. Tanaka, S. Masuda, T. Inoue, H. Yamakage, T. Kusakabe, F. Tani, A. Shimatsu, N. Takahashi, J. Ogawa, N. Satoh-Asahara, and T. Kawada. 2018. $\alpha$-Linolenic acidderived metabolites from gut lactic acid bacteria induce differentiation of anti-inflammatory M2 macrophages through G proteincoupled receptor 40. FASEB J. 32:304-318.

Portha, B., G. Lacraz, M. Kergoat, F. Homo-Delarche, M. H. Giroix, D. Bailbé, M. N. Gangnerau, M. Dolz, C. Tourrel-Cuzin, and J. Movassat. 2009. The GK rat beta-cell: A prototype for the diseased human beta-cell in type 2 diabetes? Mol. Cell. Endocrinol. 297:73-85

Sakata, T., and H. Setoyama. 1995. Local stimulatory effect of shortchain fatty acids on the mucus release from the hindgut mucosa of rats (Rattus norvegicus). Comp. Biochem. Physiol. A. Physiol. 111:429-432.

Sato, M., K. Uzu, T. Yoshida, E. M. Hamad, H. Kawakami, H. Matsuyama, I. A. Abd El-Gawad, and K. Imaizumi. 2008. Effects of milk fermented by Lactobacillus gasseri SBT2055 on adipocyte size in rats. Br. J. Nutr. 99:1013-1017.

Sedighi, M., S. Razavi, F. Navab-Moghadam, M. E. Khamseh, F. Alaei-Shahmiri, A. Mehrtash, and N. Amirmozafari. 2017. Comparison of gut microbiota in adult patients with type 2 diabetes and healthy individuals. Microb. Pathog. 111:362-369.

Shirouchi, B. K. Nagao, M. Umegatani, A. Shiraishi, Y. Morita, S. Kai, T. Yanagita, A. Ogawa, Y. Kadooka, and M. Sato. 2016. Probiotic Lactobacillus gasseri SBT2055 improves glucose tolerance and reduces body weight gain in rats by stimulating energy expenditure. Br. J. Nutr. 116:451-458.

Soares, J. B., P. Pimentel-Nunes, R. Roncon-Albuquerque, and A Leite-Moreira. 2010. The role of lipopolysaccharide/toll-like receptor 4 signaling in chronic liver diseases. Hepatol. Int. 4:659-672.

Sperry, W. M., and M. Webb. 1950. A revision of the SchoenheimerSperry method for cholesterol determination. J. Biol. Chem. 187:97-106.

Ueta, K., T. Ishihara, Y. Matsumoto, A. Oku, M. Nawano, T. Fujita, A. Saito, and K. Arakawa. 2005. Long-term treatment with the $\mathrm{Na}^{+}$-glucose cotransporter inhibitor T-1095 causes sustained improvement in hyperglycemia and prevents diabetic neuropathy in Goto-Kakizaki rats. Life Sci. 76:2655-2668.

von Scholten, B. J., E. N. Andresen, T. I. Sørensen, and T. Jess. 2013. Aetiological factors behind adipose tissue inflammation: An unexplored research area. Public Health Nutr. 16:27-35.

Wiesner, P., S. H. Choi, F. Almazan, C. Benner, W. Huang, C. J. Diehl, A. Gonen, S. Butler, J. L. Witztum, C. K. Glass, and Y. I. Miller. 2010. Low doses of lipopolysaccharide and minimally oxidized low-density lipoprotein cooperatively activate macrophages via nuclear factor kappa B and activator protein-1: Possible mechanism for acceleration of atherosclerosis by subclinical endotoxemia. Circ. Res. 107:56-65.

Xue, B., S. Sukumaran, J. Nie, W. J. Jusko, D. C. Dubois, and R. R. Almon. 2011. Adipose tissue deficiency and chronic inflammation in diabetic Goto-Kakizaki rats. PLoS One 6:e17386.

Yao, K., L. Zeng, Q. He, W. Wang, J. Lei, and X. Zou. 2017. Effect of probiotics on glucose and lipid metabolism in type 2 diabetes mellitus: A meta-analysis of 12 randomized controlled trials. Med. Sci. Monit. 23:3044-3053.

Zhang, W., A. Khan, C. G. Ostenson, P. O. Berggren, S. Efendic, and B. Meister. 2002. Down-regulated expression of exocytotic proteins in pancreatic islets of diabetic GK rats. Biochem. Biophys. Res. Commun. 291:1038-1044.

Zheng, X., Y. Qiu, W. Zhong, S. Baxter, M. Su, Q. Li, G. Xie, B. M. Ore, S. Qiao, M. D. Spencer, S. H. Zeisel, Z. Zhou, A. Zhao, and W. Jia. 2013. A targeted metabolomic protocol for short-chain fatty acids and branched-chain amino acids. Metabolomics 9:818827. 